\title{
Use of conditioned media (CM) and xeno-free serum substitute on human adipose-derived stem cells (ADSCs) differentiation into urothelial-like cells
}

\author{
Ban Alkurdi ${ }^{1}$, Nidaa A. Ababneh ${ }^{1}$, Nizar Abuharfeil ${ }^{2}$, Saddam Al Demour ${ }^{3}$, Abdalla S Awidi ${ }^{\text {Corresp. } 1,4}$ \\ ${ }^{1}$ Cell Therapy Center, University of Jordan, Amman, Jordan \\ 2 Department of Biotechnology and Genetic Engineering, Jordan University of Science and Technology, Irbid, Jordan \\ 3 Department of Urology, School of medicine, University of Jordan, Amman, Jordan, University of Jordan, Amman, Jordan \\ 4 Department of Medicine, School of Medicine, University of Jordan, Amman, Amman, Jordan \\ Corresponding Author: Abdalla S Awidi \\ Email address: abdalla.awidi@gmail.com
}

Background: Congenital abnormalities, cancers as well as injuries can cause irreversible damage to the urinary tract, which eventually requires tissue reconstruction. Smooth muscle cells, endothelial cells, and urothelial cells are the major cell types required for the reconstruction of lower urinary tract. Adult stem cells represent an accessible source of unlimited repertoire of untransformed cells.

Aim: Fetal bovine serum (FBS) is the most vital supplement in the culture media used for cellular proliferation and differentiation. However, due to the increasing interest in manufacturing xeno-free stem cell-based cellular products, optimizing the composition of the culture media and the serum-type used is of paramount importance. In this study, the effects of FBS and pooled human platelet (pHPL) lysate were assessed on the capacity of human adipose-derived stem cells (ADSCs) to differentiate into urothelial-like cells. Also, we aimed to compare the ability of both conditioned media (CM) and unconditioned urothelial cell media (UCM) to induce urothelial differentiation of ADCS in vitro.

Methods: ADSCs were isolated from human lipoaspirates and characterized by flow cytometry for their ability to express the most common mesenchymal stem cell (MSCs) markers. The differentiation potential was also assessed by differentiating them into osteogenic and adipogenic cell lineages. To evaluate the capacity of ADSCs to differentiate towards the urothelial-like lineage, cells were cultured with either CM or UCM, supplemented with either $5 \% \mathrm{pHPL}, 2.5 \% \mathrm{pHPL}$ or $10 \%$ FBS. After 14 days of induction, cells were utilized for gene expression and immunofluorescence analysis.

Results: ADSCs cultured in CM and supplemented with FBS exhibited the highest upregulation levels of the urothelial cell markers; cytokeratin-18 (CK-18), cytokeratin-19 (CK-19), and Uroplakin-2 (UPK-2), with a 6.7, 4.2- and a 2-folds increase in gene expression, respectively. Meanwhile, the use of CM supplemented with either $5 \%$ pHPL or $2.5 \%$ pHPL, and UCM supplemented with either $5 \%$ pHPL or $2.5 \%$ pHPL showed low expression levels of CK-18 and CK-19 and no upregulation of UPK-2 level was observed. In contrast, the use of UCM with FBS has increased the levels of CK-18 and CK-19, however to a lesser extent compared to CM. At the cellular level, CK-18 and UPK-2 were only detected in CM/FBS supplemented group. Growth factor analysis revealed an increase in the expression levels of EGF, VEGF and PDGF in all of the differentiated groups.

Conclusion: Efficient ADSCs urothelial differentiation is dependent on the use of conditioned media. The presence of high concentrations of proliferation-inducing growth factors present in the $\mathrm{pHPL}$ reduces the

Peer] reviewing PDF | (2020:05:48811:3:1:NEW 10 Jan 2021) 
efficiency of ADSCs differentiation towards the urothelial lineage. Additionally, the increase in EGF, VEGF and PDGF during the differentiation implicates them in the mechanism of urothelial cell differentiation. 
1 Editors comments did not require any changes to manuscript

2 Title: Use of conditioned media (CM) and xeno-free serum substitute on human adipose-

3 derived stem cells (ADSCs) differentiation into urothelial-like cells.

5 Authors: Ban Al-Kurdi ${ }^{1}$, Nidaa A. Ababneh ${ }^{1}$,Nizar M. Abuharfil' ${ }^{2}$, Saddam Al-Demour ${ }^{3}$, Abdalla

6 Awidi $^{1,4}$

7 1-Cell Therapy Center, University of Jordan, Amman, Jordan.

8 2-Department of Biotechnology and Genetic Engineering, Jordan University for Science and 9 Technology, Irbid, Jordan.

10 3-Department of Urology, School of medicine, University of Jordan, Amman, Jordan.

11 4-Department of Medicine, School of Medicine, University of Jordan, Amman, Jordan,

* Corresponding author:

Prof Abdalla Awidi. MD. FRCP

Cell Therapy Center, University of Jordan, Amman 11942, Jordan.

16 Email: aabbadi@ju.edu.jo, abdalla.awidi@gmail.com

17 Tel: +962-6-5355000 ext 23960

18 Mobile $+962-795277455$

19 Fax: +962-6-5530082

20 Word count for the abstract (270) and the main text (3647). 
22

23

\section{The authors declare no conflict of interest}

\section{Abstract}

Background: Congenital abnormalities, cancers as well as injuries can cause irreversible damage to the urinary tract, which eventually requires tissue reconstruction. Smooth muscle cells, endothelial cells, and urothelial cells are the major cell types required for the reconstruction of lower urinary tract. Adult stem cells represent an accessible source of unlimited repertoire of untransformed cells.

Aim: Fetal bovine serum (FBS) is the most vital supplement in the culture media used for cellular proliferation and differentiation. However, due to the increasing interest in manufacturing xenofree stem cell-based cellular products, optimizing the composition of the culture media and the serum-type used is of paramount importance. In this study, the effects of FBS and pooled human platelet (pHPL) lysate were assessed on the capacity of human adipose-derived stem cells (ADSCs) to differentiate into urothelial-like cells. Also, we aimed to compare the ability of both conditioned media (CM) and unconditioned urothelial cell media (UCM) to induce urothelial differentiation of ADCS in vitro.

Methods: ADSCs were isolated from human lipoaspirates and characterized by flow cytometry for their ability to express the most common mesenchymal stem cell (MSCs) markers. The differentiation potential was also assessed by differentiating them into osteogenic and adipogenic cell lineages. To evaluate the capacity of ADSCs to differentiate towards the urothelial-like lineage, cells were cultured with either conditioned (CM) or unconditioned urothelial cell media (UCM), supplemented with either 5\% pooled human platelet lysate (pHPL), $2.5 \%$ pHPL or $10 \%$ FBS. After 14 days of induction, cells were utilized for gene expression and immunofluorescence analysis.

Results: ADSCs cultured in CM and supplemented with FBS exhibited the highest upregulation levels of the urothelial cell markers; cytokeratin-18 (CK-18), cytokeratin-19 (CK-19), and Uroplakin-2 (UPK-2), with a 6.7, 4.2- and a 2-folds increase in gene expression, respectively. Meanwhile, the use of CM supplemented with either 5\% pHPL or $2.5 \% \mathrm{pHPL}$, and UCM supplemented with either $5 \%$ pHPL or $2.5 \%$ pHPL showed low expression levels of CK-18 and CK-19 and no upregulation of UPK-2 level was observed. In contrast, the use of UCM with FBS has increased the levels of CK-18 and CK-19, however to a lesser extent compared to CM. At the cellular level, CK-18 and UPK-2 were only detected in CM/FBS supplemented group. Growth factor analysis revealed an increase in the expression levels of EGF, VEGF and PDGF in all of the differentiated groups. 
56 Conclusion: Efficient ADSCs urothelial differentiation is dependent on the use of conditioned

57 media. The presence of high concentrations of proliferation-inducing growth factors present in the 58 pHPL reduces the efficiency of ADSCs differentiation towards the urothelial lineage. Additionally, 59 the increase in EGF, VEGF and PDGF during the differentiation implicates them in the mechanism 60 of urothelial cell differentiation.

Key words: adipose stem cells, urothelial cells, pooled human platelet lysate, cellular 63 differentiation

\section{Introduction}

Congenital abnormalities, cancers as well as injuries may lead to irreversible damage to the urinary tract, which eventually requires reconstruction. Early attempts on the reconstruction of urinary tract have focused on the use of acellular matrix for bladder reconstruction. Acellular matrices are immunologically inert and act in vivo as scaffolds, to recruit the progenitor cells and infiltrate the matrix to produce bladder tissue (Howard et al., 2008). The two most commonly used acellular matrices for bladder and urethral reconstruction are the small intestinal submucosa (SIS) and the bladder acellular matrix (BAM) (Staack et al., 2005). In the year 2000, the FDA approved the use of porcine collagen matrix, derived from the small intestinal submucosa, in the reconstructionbased surgical procedures (Hodde et al., 2007). However, fibrosis, matrix shrinkage and the lack of the ability to perform urothelial anastomosis are the major hurdles that must be overcome before acellular matrices can be used in the bladder and urethral reconstruction (Portis et al., 2000;

77 Campodonico et al., 2004; Azadzoi et al., 1999; Horst et al., 2019).

Adult stem cells represent an accessible source of unlimited repertoire of untransformed cells. Early attempts to incorporate stem cells in urinary tract tissue engineering culminated in using stem cells without transdifferentaition and directly implanting them in vivo (Liao et al., 2013;

81 Chung et al., 2005). Mesenchymal stem cells (MSCs) have been used in organ reconstruction by 
82 expanding them in vitro and then implanting them to induce their differentiation potential (Sharma 83 et al., 2010; Sharma et al., 2009). On the other hand, stem cells can be expanded and differentiated

84 in vitro and then transplanted directly to the affected subject. Thus, direct differentiation of stem

85 cells can reduce the time required for patient's recovery.

86 Smooth muscle cells, endothelial cells, and urothelial cells are the major cell types required for the

87 reconstruction of lower urinary tract (Qin et al., 2014). Three induction protocols have been

88

reported to induce the differentiation of stem cells towards the urothelial lineage: direct co-culture with urothelial cells, indirect co-culture system with urothelial cells, and culturing the stem cells in conditioned media (CM) derived from urothelial cell culture (Becker et al., 2007). The first protocol of direct co-culture system is inapplicable in cases of malignancies, infections, and inflammatory diseases (Liu et al., 2009; Shi et al., 2012). The indirect co-culturing is applicable in small systems such as the filter well insert (Liu et al., 2009). To the current time, the use of conditioned media represents the most favorable and easy-to-use method for induction of MSCs to urothelial cells. However, several problems still need to be addressed before using these cells in clinical therapy, including the limited differentiation capability (transdifferentaition efficiency ranges from $40-70 \%$ ) and the presence of xenogeneic substances such as fetal bovine serum (FBS) in cell culture media (Zhang et al., 2014; Shi et al., 2012).

Fetal bovine serum is the most vital supplement used in cell culture media for cell proliferation and differentiation. However, due to its limited supply and the increased demand on manufacturing xeno-free stem cell-based cellular products, optimizing the composition of culture media and the type of serum used are of critical importance.

Human platelet lysate (HPL) is defined by Marx as "the volume of plasma fraction of autologous blood having a platelet concentration above baseline". It has been reported that HPL enhances the 
105 proliferation and differentiation of MSCs compared to xenogenic FBS (Kakudo, et al., 2008;

106 Lucarelli, et al., 2003; Li, 2013; Mishra, et al., 2009; Cervellia, et al., 2012). These effects make

107 the HPL as an attractive alternative that can be used in MSCs culture with minimal adverse effects

108 in clinical settings. In this study, the effects of FBS and pooled human platelet (pHPL) lysate were

109 assessed on the capacity of huADSCs to differentiate into urothelial-like cells. Also, we aimed to

110 compare the ability of both conditioned media (CM) and unconditioned urothelial cell media

111 (UCM) to induce urothelial differentiation of ADCS.

\section{Methods}

\section{Material and reagents:}

114 Dulbecco's Modified Eagle's Medium DMEM (GIBCO, USA), collagenase type 1 (Worthington,

115 Lakewood, NJ), FBS (GIBCO, USA), streptomycin and penicillin and $20 \mathrm{mM}$ L-glutamine 116 (Euroclone, Italy), 0.25\% trypsin-0.04\% EDTA (GIBCO, USA), (SV-HUC-1) ATCC (CRL117 9520), StemPro Adipogenesis differentiation media (Invitrogen, USA), Trizol reagent (Invitrogen, 118 USA), Human MSC Analysis Kit (BD, USA), iScript reverse transcription supermix (BioRad, 119 USA), iQTM SYBR mix (BioRad, USA), cytokeratin-18 (Abcam, ab668, 1:200), uroplakin-2 120 (Santa Cruz, sc-15178, 1:50), ELISA kits (Abcam, UK).

\section{Cell culture:}

122 All experimental protocols involving human tissues were approved by the Ethics Committee at the 123 King Abdullah Hospital, School of Medicine, Jordan University of Science and Technology (IRB 124 No: IRB/7/2019). After obtaining signed informed consents, human adipose tissue aspirates were obtained from 3 individuals, aged 30, 31 and 35, who underwent liposuction procedures. ADSCs

126 were isolated as previously described (Francis et al., 2010). Briefly, adipose tissue aspirates were 
127 digested with $0.1 \%$ collagenase type 1 (Worthington, Lakewood, NJ) in PBS, for 45 minutes at

$12837^{\circ} \mathrm{C}$, with gentle shaking every five minutes. The enzyme was then diluted with an equal amount 129 of complete cell culture medium consisting of DMEM (GIBCO, USA) supplemented with 10\% 130 FBS (GIBCO, USA), 1\% streptomycin and penicillin and $20 \mathrm{mM}$ L-glutamine (Euroclone, Italy).

131 The suspension was centrifuged at $1200 \mathrm{xg}$ for 10 minutes and then the pellet was resuspended in

$1325 \mathrm{ml}$ complete cell culture medium. After that, the cell suspension was passed through a $70 \mu \mathrm{m}$ 133 cell strainer and centrifuged at $500 \mathrm{xg}$ for 10 minutes. The obtained cells were counted and seeded 134 at a density of $2 \times 10^{5}$ cells $/ \mathrm{cm}^{2}$ in a tissue culture flask and incubated at $37{ }^{\circ} \mathrm{C}$ and $5 \% \mathrm{CO}_{2}$. The 135 medium was changed every two to three days until the adherent ADSCs became 70-80\% confluent. 136 Cells were detached with $0.25 \%$ trypsin-0.04\% EDTA (GIBCO, USA) solution, and the resulting 137 ADSCs at passage 3-5 were used for further experiments. SV40 immortalized human ureter 138 urothelium (SV-HUC-1) cell line was obtained from ATCC (CRL-9520). SV-HUC-1 cells were 139 cultured in F-12K medium supplemented with 10\% FBS and 1\% streptomycin and penicillin. 140 Conditioned medium derived from SV-HUC1 was collected and used to induce the ADSCs 141 differentiation towards the urothelial-like cell lineage.

\section{Flow cytometry}

143 Cultured ADSCs at passage 3 and 70\% confluency were utilized for cell surface marker 144 assessment. Cells were detached using TrypLE (GIBCO, USA) and washed twice with FACS 145 buffer (PBS, 1\% FBS). Then, cells were counted and adjusted to $10^{6}$ cells $/ \mathrm{ml}$. Aliquots of $100 \mu 1$ 146 were placed in test tubes and incubated with fluorochrome-conjugated antibodies using Human 147 MSC Analysis Kit (BD, USA), which includes: CD-44, CD-105, CD-73, CD-90 and a negative 148 cocktail includes: CD-34, CD-11b, CD-19, CD-45 and HLA-DR mix for 30 minutes in the dark, 149 according to the manufacturer's instructions. Cells were then centrifuged at $300 \mathrm{xg}$ for 5 minutes 
150 and resuspended in $500 \mu 1 \mathrm{FACS}$ buffer. The analysis was performed using BD FACSCanto ${ }^{\mathrm{TM}}$ and

151 the data were analyzed using Diva software.

\section{Multilineage Differentiation}

153 Adipogenic differentiation was performed using StemPro Adipogenesis differentiation media

154 (Invitrogen, USA) for 14 days. After that, cells were washed twice with PBS, fixed in 4\%

155 formaldehyde for 15 minutes and stained with oil red $\mathrm{O}$ stain, to confirm the presence of 156 adipocytes. StemPro Osteogenic differentiation kit (Invitrogen, USA) was used to induce ADSCs 157 differentiation towards the osteogenic lineage. After 21 days in culture, differentiated cells were 158 washed, fixed in 4\% formaldehyde for 15 minutes, and stained with Alizarin Red S (ARS) stain, 159 to verify the osteogenic differentiation. Cells under normal culture conditions were used as 160 negative controls.

161

162

163

164

165

166

167

168

169

170

171

172

\section{Preparation of Pooled Human Platelet Lysate (pHPL)}

Platelet bags designated as platelet-rich plasma 1 (PRP1) were obtained from Jordan University Hospital/blood bank unit. Briefly, platelet bags from 17 donors were pooled in one container and centrifuged at $700 \mathrm{xg}$ for 17 minutes at $18{ }^{\circ} \mathrm{C}$. After centrifugation, the platelets pellet was formed and the supernatant was designated as platelet-poor plasma (PPP). The latter was transferred into new sterile tubes, and platelets obtained from $1 \mathrm{ml}$ PRP1 were resuspended in $300 \mu 1$ of PPP, this was designated as PRP2. Following that, platelets concentration was adjusted to $2 \times 10^{6}$ platelets $/ \mu 1$ with PPP, and lysed through two freeze/thaw cycles at $-20^{\circ} \mathrm{C}$ and then at $37^{\circ} \mathrm{C}$. Platelet fragments were removed by centrifugation at $3000 \mathrm{xg}$ for 20 minutes at $18^{\circ} \mathrm{C}$ and filtrated through a $0.2 \mu \mathrm{m}$ filter. The obtained supernatant is now called pHPL. The pHPL was aliquoted and stored at -20 ${ }^{\circ} \mathrm{C}$. Upon supplementing the media with $10 \% \mathrm{pHPL}, 2 \mathrm{IU} / \mathrm{mL}$ of heparin was added to prevent coagulation. 


\section{Differentiation of ADSCs into Urothelial-like Cells}

174 When SV-HUC1 cells cultured in F-12K medium reached $80-90 \%$ confluency, medium was 175 collected every 24 hours and changed into fresh medium for two sequential days. Next, collected 176 medium was centrifuged at $3000 \mathrm{rpm}$ for 5 minutes, pooled and filtered through a $0.22 \mu \mathrm{m}$ filter 177 and stored at $-20^{\circ} \mathrm{C}$. For urothelial induction, ADSCs were seeded at a density of 500 cells $/ \mathrm{cm}^{2}$ and 178 cultured with either conditioned or unconditioned medium (UCM) at a ratio of 1:4 F-12K: DMEM, 179 supplemented with either 5\% pHPL, 2.5\% pHPL or 10\% FBS. Uninduced controls were also 180 included. On day 14 post-induction, cells were utilized for immunofluorescence staining and RNA 181 extraction for relative gene expression analysis. qRT-PCR Gene Expression Analysis of Urothelial Markers

183 Total RNA was isolated at day 14 of urothelial differentiation using Trizol reagent (Invitrogen, 184 USA) and subsequently purified with RNeasy mini kit (Qiagen, USA). cDNA was synthesized 185 using iScript reverse transcription supermix (BioRad, USA). Quantitative RT-PCR (qPCR) 186 reactions were performed using $\mathrm{iQ}^{\mathrm{TM}}$ SYBR mix (BioRad, USA) and 300nM of each forward and 187 reverse primers. Primer sequence and product size are provided in Table 1.

\section{Immunofluorescence staining of Urothelial Markers}

After 14 days of induction, cells on coverslips were fixed in $4 \%$ formaldehyde for 15 minutes and permeabilized with PBS/0.1\% Triton X-100 for 5 minutes. To prevent nonspecific binding, cells were incubated with blocking solution (3\% BSA (wt/v) and 0.3\% Triton X-100 (v/v) in PBS) for 60 minutes. Cells were then incubated with the primary antibodies against cytokeratin-18 (Abcam, ab668, 1:200) and uroplakin-2 (Santa Cruz, sc-15178, 1:50), diluted in blocking buffer overnight at $4^{\circ} \mathrm{C}$ in a humid chamber. Subsequently, cells were incubated with the appropriate secondary 
196

197 mounting with mounting media (Invitrogen, USA).

temperature followed by counterstaining with DAPI (4',6-diamidino-2-phenylindole) and

198 Enzyme Linked Immunosorbent Assay (ELISA)

199 The secretion of epidermal growth factor (EGF), vascular endothelial growth factor (VEGF), and 200 platelet-derived growth factor (PDGF-BB) in conditioned and unconditioned culture medium was 201 measured using ELISA kits (Abcam, UK), according to the manufacturer's instructions. For 202 growth factors measurement, fresh serum-free media was added on day 14 of urothelial induction 203 and collected after 24 hours. Triplicate samples were run in 96-well plates coated with an antibody 204 specific to a particular growth factor mentioned above. The absorbance was measured at $450 \mathrm{~nm}$ 205 and within 30 minutes of completing the assay.

\section{Statistical Analysis}

207 All the experiments were performed at least three times, and statistical analysis was performed using SPSS 20.0. The data were represented as the mean \pm standard error of the mean (SEM) and tested for normality and equal variance before analysis using the Shapiro-Wilk test. Statistical differences were calculated using analysis of variance (ANOVA) and Post-hoc test for comparison between groups. The analysis of ELISA data was performed using Graphpad Prism for curve fitting and independent t-test for significance calculation. Differences were considered significant

213 at $P<0.05$.

\section{Results}

\section{Isolation and Characterization of ADSCs}

216 Cells with fibroblastic morphology were adhered to the tissue culture plate and reached the confluency within two weeks of the initial plating (Figure 1A). Flow cytometry staining of the most common MSC markers showed positive expression of the following markers: CD-44 (100\%), 
219 CD-105 (89.8\%), CD-73 (99.9\%), and CD-90 (100\%) (Figure 1B-E). To confirm the purity of the

220 isolated ADSCs from the hematopoietic stem cell contamination, flow cytometry staining was

221 performed and demonstrated minimal expression levels of the negative cocktail markers (Figure

222 1F). To further validate the stemness of the isolated cells, ADSCs were transdifferentiated into the

223 osteogenic and adipogenic cell lineages. Following 21 days of the osteogenic induction, cells

224 exhibited flattened and more elongated morphology with extracellular calcium phosphate deposits

225 as confirmed by Alizarin red S (ARS) staining. These deposits were absent in the uninduced

226 ADSCs cultured in cell culture media (Figure 2 A-D). Additionally, adipogenic differentiation

227 showed intracellular localization of lipid droplets. These droplets were positively stained with oil

228 red $\mathrm{O}$, and were absent in the uninduced negative control. Thus, the successful differentiation of

229 ADSCs into osteoblasts and pre-adipocytes confirmed the multipotency of these cells (Figure 2 E-

$230 \mathrm{H})$.

\section{Urothelial cell markers detection by qRT-PCR}

232 To evaluate the capacity of ADSCs to differentiate towards the urothelial-like lineage, cells were

233 cultured with either conditioned $(\mathrm{CM})$ or unconditioned urothelial cell media (UCM),

234 supplemented with either 5\% pooled human platelet lysate (pHPL), 2.5\% pHPL or 10\% FBS. After

23514 days of induction, cells were utilized for further experiments. To analyze the effect of induction

$236 \mathrm{CM}$ and UCM media on the differentiation of ADSCs towards the urothelial lineage, we measured

237 the gene expression levels of two cytokeratin proteins; CK-18 and CK-19 and one uroplakin

238 protein (UPK-2), expressed by the urothelial cells (Figure 3). CK-18 and CK-19 are considered as

239 early markers of urothelial cell specification, and uroplakin proteins representing the terminal

240 maturation stage. The levels of CK-18 expression were not significantly altered in groups treated

241 with $\mathrm{CM}$ supplemented with either 5\% or 2.5\% pHPL (P> 0.05). Meanwhile, a 6.7-fold 
242 upregulation in CK-18 expression compared to the uninduced control was observed in CM FBS

243 treated group $(\mathrm{P}=0.006)$ (Figure 3A). Additionally, UCM increased CK-18 expression of 3-fold in

244 the presence of either FBS or pHPL relative to the uninduced cells (P-Value). On the other hand,

245 culturing ADSCs in CM supplemented with FBS exhibited the highest upregulation level of CK-

24619 with a 4.2-fold increase compared to the uninduced control $(\mathrm{P}=0.01)$. In contrast, $\mathrm{CM} 2.5 \%$

247 pHPL and CM 5\% pHPL failed to upregulate the expression of CK-19. Whereas, UCM-FBS

248 induced CK-19 expression, but to a lesser extent compared to CM-FBS. On the contrary, UCM

249 supplemented with 5\% and 2.5\% pHPL failed to upregulate the expression of CK-19 (Figure 3B).

250 Regarding the UPK-2 terminal differentiation marker, only CM-FBS and UCM-FBS cultures

251 showed an increased level of expression of approximately 2-fold compared to control cells (Figure

$2523 \mathrm{C})$.

253

254 Detection of Urothelial Cell Markers by Immunofluorescence

255 Since gene expression results suggest an enhanced cellular differentiation using CM culture 256 conditions, we compared the expression of CK-18 (early differentiation marker) and UPK-2 (late

257 differentiation marker) between pHPL and FBS supplemented cultures by immunofluorescence

258 staining (Figure 4). Staining revealed that CM supplemented with FBS resulted in a 2.5-fold

259 increase in the expression of CK-18 early differentiation marker and a 2-fold increase in UPK-2

260 expression compared to non-induced ADSCs control (Figure 4 A \& B). Whereas groups treated

261 with CM \& 5\% pHPL or 2.5\% pHPL failed to elicit the same response (Figure 4 A \& C).

262 Assessment of growth factor levels of induced ADSCs by ELISA

263 To assess changes in the growth factor levels produced by the induced cells, we measured the

264 levels of EGF, PDGF-BB, and VEGF, the main growth factor proteins secreted by cells into the 
265 culture medium. Following 14 days of urothelial induction, measurement of the growth factors in

266 serum-free media collected after 24 hours resulted in the detection of higher levels of these factors

267 in cells treated with CM compared to their counterparts cultured in UCM (Figure 5). Additionally, 268 cells cultured in 5\% pHPL produced higher levels of EGF, PDGF-BB, and VEGF. Levels of VEGF

269 were significantly higher in CM-5\% pHPL, CM-2.5\% pHPL and UCM-pHPL $(P=0.009,0.023$,

270 0.004, respectively). Cells in FBS containing media showed the least amount of secretion of all

271 three growth factors. Whereas, CM-FBS elicited higher levels of growth factors compared to

272 UCM-FBS with 1.4-fold, 2.5-fold, and 2.6-fold difference for EGF, PDGF-BB, and VEGF, 273 respectively (Figure 5).

\section{4}

275

276 


\section{Discussion}

278 Currently, cell-based therapy and tissue engineering studies mostly rely on the ex-vivo expansion 279 and differentiation of many cell types especially stem cells. The preferential use of MSCs over 280 other types of stem cells is related to their ability to cross lineage commitment, they differentiate 281 efficiently into many cell types, and their inability to form teratomas or tumors in vivo (Qin et al., 282 2014). Furthermore, MSCs exhibit low immunogenicity and possess immunosuppressive 283 capabilities, facilitating their use in allogenic stem cell transplantation studies (Klyushnenkova et 284 al., 2005; Le Blanc et al., 2004). However, the clinical use of MSCs is hampered by their limited 285 availability, growth variability, invasive collection procedures, and the use of xenogeneic sources of serum such as FBS during the expansion and differentiation procedures. Conditioned medium is widely used to induce MSC differentiation into chondrocytes, osteocytes, dopaminergic neurons, cholinergic neurons as well as urothelial cells (Alves da Silva et al., 2015; Heino et al.,2004; Aliaghaei et al., 2016; Borkowska et al., 2015; Zhang et al., 2014).

Different types of MSCs have been differentiated efficiently towards urothelial cells using urothelial cell-derived $\mathrm{CM}$ or FBS, making them an attractive source for urinary tract tissue regeneration (Shi et al., 2012; Zhang et al., 2013). However, a cell line-derived CM might contain many undefined factors, which could influence the cells in a myriad of ways. In addition, the use of FBS carries the risk of infectious disease transmission and immunization, which results in restricting the use of such system in a clinical setting (Heiskanen et al., 2007; Sundin et al., 2007). Thus, for the future translational purposes, we aimed to assess the ability of unconditioned urothelial cell media to substitute cell line-derived CM and pHPL as alternative to FBS, to induce ADSCs differentiation towards urothelial cells. 
299 Our results indicate that although ADSCs are capable of expressing early differentiation markers

300 of urothelial like cells such as CK-18 and CK-19 when cultured in CM, this expression is minimal

301 and could not be detected at the cellular level as observed by immunostaining. On the other hand,

302 terminal differentiation phenotype associated with the expression of UPK-2 is only achievable in

303 the presence of CM. This confirms the presence of certain signaling factors in the CM that act in

304 a paracrine manner and are essential for the induction process. Zhang et al., reported an increased

305 level of expression of a panel of cytokines and growth factors following 12 hours of induction of

306 ADSC into urothelial cells (Zhang et al., 2013). However, after 21 days of induction, the levels

307 normalized slowly until they reached a level similar to the baseline level seen before the induction

308 process (Zhang et al., 2013). Thus, a critical timing window for the differentiation process is

309 crucial during the early and intermediate stages of differentiation.

310 Since UCM by itself lead to a minimal increase in the urothelial markers, an addition of growth

311 factors and cytokines during this critical timing window might increase the differentiation

312 potential. In a previous study, the addition of FGF-10 to Warton jelly-derived MSC induced their

313 differentiation towards urothelial cells, as evident by the co-expression of CK-8 and UPK-III

314 (Chung \& Koh, 2014). In a similar manner, discovering more of such inductive factors paves the

315 way for the generation of a defined differentiation system.

316 Here we report increased levels of EGF, VEGF, and PDGF-BB growth factors when cells were

317 cultured in urothelial cell-derived CM. Several other studies also showed elevated levels of 318 secretion when either ADSCs or BMSCs are cultured under the same conditions (Tian et al., 2010;

319 Shi et al., 2012; Zhang et al., 2014). EGF plays a crucial role in inducing early ESC differentiation 320 towards the endodermal lineage (Cras-Méneur et al., 2001; Kumar et al., 2014). However, 321 induction of terminal urothelial differentiation in vitro with PPAR $\gamma$ activators requires the 
322 inhibition of EGF pathway (Varley et al., 2004a, 2004b, 2006). Thus, the requirement of EGF

323 might be essential during the early stages of induction, to induce a basal urothelial phenotype and

324 it should be followed by inhibition stage in order to produce the terminal superficial urothelial

325 phenotype.

326 It has been indicated that PDGF can induce proliferation and differentiation of cells originating

327 from all three germ layers including lung, microvilli, gastrointestinal and endothelial cell

328 development based on the normal PDGF signaling (Boström et al. 2002; Karlsson et al. 2000; Utoh

329 et al. 2003; Ding et al. 2004; Calver et al. 1998). Additionally, PDGF is known to be secreted by

330 endothelial and epithelial cells and it regulates the proliferation and differentiation of neighboring

331 smooth muscle cells (Bostrom et al 2002, Barkauskas 2013).

332 On the other hand, VEGF mediates MSC differentiation towards the endothelial cell lineage via

333 the Rho/MRTF-A pathway (Wang et al., 2013). Although the major role of VEGF is played during

334 vasculoneogensis and cardiac development, it also contributes significantly to the development of

335 organs of endodermal origin including liver, lungs and pancreas (Carmeliet et al., 1999; Giordano

336 et al., 2001; Lammert et al; 2001; Matsumoto et al., 2001; Compernolle et al., 2002).

337 Even though the role of these growth factors during the differentiation, development and 338 organogenesis is well-established, a need arises to characterize the extent of involvement of each 339 of these factors in the induction of urothelial cell differentiation. The general consensus on the 340 mechanism of action of conditioned medium is the presence of undefined soluble factors released

341 by the differentiated cells as a way of intercellular communications. These biologically active

342 factors act in a paracrine manner and trigger an internal signaling pathways in MSCs, directing

343 them to differentiate towards a certain lineage (Alves da Silva et al., 2015; Zhang et al., 2014).

344 These differentiated cells in turn secrete bioactive factors, which act in an autocrine and paracrine 
manner to maintain the differentiated state of the cells, as well as inducing the differentiation of neighboring cells (Alves da Silva et al., 2015; Zhang et al., 2014; Shi et al., 2012).

347 In terms of serum choice, we found that pHPL is not an efficient alternative for urothelial 348 differentiation at a concentration of $5 \%$ and $2.5 \%$. Substituting FBS with pHPL during the 349 differentiation reduces the expression of urothelial related markers.

350 Several studies reported an increase in the differentiation potential of several types of MSCs 351 towards the osteogenic, myofibroblastic, cardiomyogenic and adipogenic cell lineages in the 352 presence of pHPL as a serum substitute (Karadjian et al., 2020; Samuel et al., 2017; Chignon353 Sicard et al., 2017; Homayouni Moghadam et al., 2016). On the other hand, pHPL decreased the 354 ability of certain types of stem cells to differentiate into osteoblasts, chondrocytes and adipocytes (Gruber et al., 2004; Lee et al., 2014; Chignon-Sicard et al., 2017). Thus, the response elicited towards the presence of pHPL in the culture media is affected by the stem cell type, the differentiation lineage, and the percentage of pHPL used in the culture media. MSC including ADSCs have an increased proliferative capacity in the presence of pHPL (Karadjian et al., 2020; Naaijkens et al., 2012, Kølle et al., 2013). As urothelial cells differentiate from the basal layer towards the superficial layer, they lose their ability to regenerate. Thus, the molecular circuitry governing differentiation depends on a skew towards differentiation by reducing proliferation, which probably could not be achieved in the presence of pHPL.

In conclusion, the induction of ADSCs towards the urothelial phenotype requires the presence of both $\mathrm{CM}$ and FBS. Substituting CM with UCM and FBS with pHPL significantly impacts the

365 differentiation process. The levels of EGF, VEGF, and PDGF have increased during the 366 differentiation process and thus might play an essential role in defining the mechanism of action of CM directed differentiation. Additionally, we found that $\mathrm{pHPL}$ at $5 \%$ and $2.5 \%$ concentrations 
368 negatively influenced the differentiation process. This might be explained by a skew in cellular 369 circuitry towards the proliferation rather than the differentiation process. Changing MSCs 370 microenvironment to accommodate the urothelial cells microenvironment is a basic requirement 371 for any successful differentiation protocol. This can be achieved by the addition of defined soluble

372 factors, direct or indirect co-culture with differentiated cells, the use of conditioned media or direct

373 implantation in vivo. Urothelial cell-derived CM represents a practical and efficient way for 374 ADSCs differentiation into urothelial lineage. However, a demand arises to formulate a defined 375 media that efficiently induces MSC differentiation towards the urothelial lineage for clinical 376 purposes.

\section{Funding}

388 This work was supported by the deanship of research at the University of Jordan and the Jordan 389 University for Science and Technology. 


\section{Authors' contributions}

391

392

393

394

395

396

397

398

399

400

401

402

403

404

405

406

407

408

409

410

411

412

413

414

415

416

417

418

419

420

421

422

423

424 425

Conceived and designed the experiments: BK and AA. Performed the experiments: BK and NA.

Analyzed the data: BK and SD. Wrote the manuscript: BK and NA.

\section{Competing interests}

The authors declare that they have no competing interests.

\section{References}

Howard, D., Buttery, L. D., Shakesheff, K. M., Roberts, S. J. (2008). Tissue engineering: strategies, stem cells and scaffolds. Journal of Anatomy, 213(1), 66-72.

Staack, A., Hayward, S. W., Baskin, L. S., Cunha, G. R. (2005). Molecular, cellular and developmental biology of urothelium as a basis of bladder regeneration. Differentiation , 73(4), 121-133.

Hodde JP, Johnson CE.(2007). Extracellular matrix as a strategy for treating chronic wounds. American Journal of Clinical Dermatology, 8(2), 6-15.

Portis, A. J., Shay Shalhav, A. L., Brewer, A., Humphrey, P., Mcdougall, E. M., Clayman, R. V. (2000). Laprascopic augmentation cyctoplasty with different biodegradable grafts in an animal model. The journal of urology, 164(3), 1405-1411.

Campodonico, F., Benelli, R., Michelazzi, A., Ognio, E., Toncini, C., \& Maffezzini, M. (2004). Bladder cell culture on small intestinal submucosa as bioscaffold: Experimental study on engineered urothelial grafts . European Urology, 46(4), 531-537.

Azadzoi, K. M., Tarcan, T., Siroky, M. B., \& Krane, R. J. (1999). Atherosclerosis-induced chronic ischemia causes bladder fibrosis and non-comp;iance in the rabbit. The Journal of Urology, 161(5), 1626-1635.

Liao, W., Yang, S., Song, C., Li, X., Li, Y., \& Xiong, Y. (2013). Construction of ureteral grafts by seeding bone marrow mesenchymal stem cells and smooth muscle cells into bladder acellular matrix . Transplantation Proceedings, 45(2), 730-734.

Chung, S. Y., Krivorov, N. P., Rausei, V., Thomas, L., Frantzen, M., Landsittel, D., J.Fuchs, G. (2005). Bladder reconstruction with bone marrow derived stem cells seeded on small 
intestinal submucosa improves morphological and molecular composition. The Journal of Urology , 174(1), 353-359.

Sharma, A., Fuller, N., Sullivan, R., Fulton, R., Hota, R., Harrington, D., Villano, J., Hagerty, J., Cheng, E. (2009). Defined populations of bone marrow derived mesenchymal stem and endothelial progenitor cells for bladder regeneration. The Journal of Urology, 182(2), 1898 -1905 .

Sharma, A., Hota, P., Matoka, D., Fuller,D., Jandali, D., Thaker,D ., Ameer, G., Cheng, E. (2010). Urinary bladder smooth muscle regeneration utilizing bone marrow derived mesenchymal stem cell seeded elastomeric poly(1,8-octanediol-co-citrate) based thin films. Biomaterials, 31(1), 6207-6217.

Qin, D., Long, T.,Deng, J., Zhang, Y. (2014). Urine-derived stem cells for potential use in bladder repair. Stem Cell Research and Therapy, 5(3), 69-79.

Becker, C., \& Jakse, G. (2007). Stem cells for regeneration of urological structures. European Urology, 51(5), 1217-1228.

Liu, J., Huang, J., Lin, T., Zhang, C., \& Yin, X. (2009). Cell-to-cell contact induces human adipose tissue-derived stromal cells to differentiate into urothelium-like cells in vitro. Biochemical and Biophysical Research Communications, 390(3), 931-936.

Shi, M., Zhang, Z., Xu, R., Lin, H., Fu, J., Zou, Z., Wang, F.S. (2012). Human mesenchymal stem cell transfusion is safe and improves liver function in acute-on-chronic liver failure patients. Stem Cells Translational Medicine, 1(10), 725-731.

Zhang, M., Xu, M.,Zhou, Z., Zhang, K., Zhou, J., Zhao, Y., Wang, Z., Lu, M. (2014) The differentiation of human adipose-derived stem cells towards a urothelium-like phenotype in vitro and the dynamic temporal changes of related cytokines by both paracrine and autocrine signal regulation. PLoS One. 9(4), e11786.

Francis, M. P., Sachs, P. C., Elmore, L. W., \& E. Holt, S. (2010). Isolating adipose-derived mesenchymal stem cells from lipoaspirate blood and saline fraction. Organogenesis, 6(1), $11-14$.

Klyushnenkova, E., Mosca, J. D., Zernetkina, V., Majumdar, M. K., Beggs, K. J., Simonetti, D. W., McIntosh, K. R. (2005). T cell responses to allogeneic human mesenchymal stem cells: immunogenicity, tolerance, and suppression. Journal of Biomedical Sciences, 12(1), 47-57.

Le Blanc, K., Tammik, L., Sundberg, B., Haynesworth, S. E., Ringden, O. (2003). Mesenchymal stem cells inhibit and stimulate mixed lymphocyte cultures and mitogenic responses independently of the major histocompatibility complex. Scandinavian Journal of Immunology, 57(1), 11-20.

Alves da Silva, M.L., Costa-Pinto, A.R., Martins, A., Correlo, V.M., Sol, P., Bhattacharya, M., Faria, S., Reis, RL., Neves, N.M. (2015). Conditioned medium as a strategy for human 
stem cells chondrogenic differentiation. Journal of Tissue Engineering and Regenerative Medicine, 9(6), 714-23.

Heino, T.J., Hentunen, T.A., Väänänen, H.K. (2004). Conditioned medium from osteocytes stimulates the proliferation of bone marrow mesenchymal stem cells and their differentiation into osteoblasts. Experimental Cell Research, 294(2), 458-68.

Aliaghaei, A., Gardaneh, M., Maghsoudi, N., Salehinejad, P., Gharib, E. (2016). Dopaminergic Induction of Umbilical Cord Mesenchymal Stem Cells by Conditioned Medium of Choroid Plexus Epithelial Cells Reduces Apomorphine-Induced Rotation in Parkinsonian Rats. Archive of Iranian Medecine, 19(8), 561-70.

Borkowska, P., Fila-Danilow, A., Paul-Samojedny, M., Kowalczyk, M., Hart, J., Ryszawy, J., Kowalski, J. (2015). Differentiation of adult rat mesenchymal stem cells to GABAergic, dopaminergic and cholinergic neurons. Pharmacological Reports, 67(2), 179-86.

Zhang, M., Peng, Y., Zhou, Z., Zhou, J., Wang, Z., Lu, M. (2013). Differentiation of human adiposederived stem cells co-cultured with urothelium cell line toward a urothelium-like phenotype in a nude murine model. Urology, 81(2), 465-475.

Heiskanen, A., Satomaa, T., Tiitinen, S., Laitinen, A., Mannelin, S., Impola, U., Mikkola, M., Olsson, C., Miller-Podraza, H., Blomqvist, M., Olonen, A., Salo, H., Lehenkari, P., Tuuri, T., Otonkoski, T., Natunen, J., Saarinen, J., Laine, J. (2007). Nglycolylneuraminic acid xenoantigen contamination of human embryonic and mesenchymal stem cells is substantially reversible. Stem Cells, 25(1), 197-202.

Sundin, M., Ringdén, O., Sundberg, B., Nava, S., Götherström, C., Le Blanc, K. (2007). No alloantibodies against mesenchymal stromal cells, but presence of anti-fetal calf serum antibodies, after transplantation in allogeneic hematopoietic stem cell recipients. Haematologica, 92(9), 1208-15.

Chung, S.S., Koh, C.J. (2013). Bladder cancer cell in co-culture induces human stem cell differentiation to urothelial cells through paracrine FGF10 signaling. In Vitro Cellular and Developmental Biology. Animal. 49(10), 746-51.

Tian, H., Bharadwaj, S., Liu, Y., Ma, P. X., Atala, A., \& Zhang, Y. (2010). Differentiation of Human Bone Marrow Mesenchymal Stem Cells into Bladder Cells: Potential for Urological Tissue Engineering. Tissue Engineering. Part A, 16(5), 1769-79.

Cras-Méneur, C., Elghazi, L., Czernichow, P., Scharfmann, R. (2001). Epidermal growth factor increases undifferentiated pancreatic embryonic cells in vitro: a balance between proliferation and differentiation. Diabetes, 50(7),1571-9.

Kumar, S. S., Alarfaj, A. A., Munusamy, M. A., Singh, A. J. A. R., Peng, I.-C., Priya, S. P., Higuchi, A. (2014). Recent Developments in $\beta$-Cell Differentiation of Pluripotent Stem Cells Induced by Small and Large Molecules. International Journal of Molecular Sciences, 15(12), 23418-47.

Varley, C.L., Garthwaite, M.A., Cross, W., Hinley, J., Trejdosiewicz, L.K., southgate, J. (2006). PPARgamma-regulated tight junction development during human urothelial cytodifferentiation. Journal of Cellular Physiology, 208 (2), 407-417. 
514

515 Varley, C.L., Stahlschmidt, J., Lee, W.C., Holder, J., Diggle, C., Selby, P.J., Southgate, J. (2004a).

516

517

518

519

520

521

522

523

524

525

526

527

528

529

530

531

532

533

534

535

536

537

538

539

540

541

542

543

544

545

546

547

548

549

550

551

553

554

Role of PPARgamma and EGFR signalling in the urothelial terminal differentiation program. Journal of Cell Science, 117(10), 2029-36.

Varley, C.L., Stahlschmidt, J., Smith, B., Stower, M., Southgate, J. (2004b). Activation of peroxisome proliferator-activated receptor-gamma reverses squamous metaplasiaand induces transitional differentiation in normal human urothelial cells. The American Journal of Pathology, 164 (5), 1789-98.

Boström, H., Gritli-Linde, A., Betsholtz, C. (2002). PDGF-A/PDGF alpha-receptor signaling is required for lung growth and the formation of alveoli but not for early lung branching morphogenesis. Developmental Dynamics, 223(1), 155-62.

Karlsson L., Lindahl P., Heath J.K., Betsholtz C. (2000). Abnormal gastrointestinal development in PDGF-A and PDGFR- $\alpha$ deficient mice implicates a novel mesenchymal structure with putative instructive properties in villus morphogenesis. Development. 127(16), 3457-66.

Utoh R., Shigenaga S., Watanabe Y., Yoshizato K. (2003). Platelet-derived growth factor signaling as a cue of the epithelial-mesenchymal interaction required for anuran skin metamorphosis. Developmental Dynamics, 227(2), 157-169.

Ding H., Wu X., Boström H., Kim I., Wong N., Tsoi B., O’Rourke M., Koh G.Y., Soriano P., Betsholtz C. (2004). A specific requirement for PDGF-C in palate formation and PDGFR- $\alpha$ signaling. Nature Genetics, 36(10), 1111-6.

Calver A.R., Hall A.C., Yu W.P., Walsh F.S., Heath J.K., Betsholtz C., Richardson W.D. (1998). Oligodendrocyte population dynamics and the role of PDGF in vivo. Neuron, 20(5), 86982 .

Barkauskas, C.E., Cronce, M.J., Rackley, C.R., Bowie, E.J., Keene, D.R., Stripp,B. R., Hogan, B.L.M. (2013). Type 2 alveolar cells are stem cells in adult lung. The Journal of Clinical Investigation, 123(7), 3025-36.

Wang, N., Zhang, R., Wang, S.J., Zhang, C.L., Mao, L.B., Zhuang, C.Y., Tang, Y.Y., Luo, X.G., Zhou, H., Zhang, T.C. (2013). Vascular endothelial growth factor stimulates endothelial differentiation from mesenchymal stem cells via Rho/myocardin-related transcription factor--a signaling pathway. The International Journal of Biochemistry and Cell Biology, 45(7), 1447-56.

Carmeliet P1, Ferreira V, Breier G, Pollefeyt S, Kieckens L, Gertsenstein M, Fahrig M, Vandenhoeck A, Harpal K, Eberhardt C, Declercq C, Pawling J, Moons L, Collen D, Risau W, Nagy A. (1996). Abnormal blood vessel development and lethality in embryos lacking a single VEGF allele. Nature, 380(6573), 435-9.

Giordano, F.J., Gerber, H.P., Williams, S.P., VanBruggen, N., Bunting, S., Ruiz-Lozano, P., Gu, Y., Nath, A.K., Huang, Y., Hickey, R., Dalton, N., Peterson, K.L., Ross, J.J., Chien, K.R., Ferrara, N. (2001). A cardiac myocyte vascular endothelial growth factor paracrine 
557 558

559 560

561 562

563

564

565

566

567

568

569

570

571

572

573

574

575

576

577

578

579

580

581

582

583

584

585

586

587

588

589

590

591

592

593 pathway is required to maintain cardiac function. Proceeding of the National Academy of Science USA, 98(10), 5780-5.

Lammert, E., Cleaver, O., Melton, D. (2001). Induction of pancreatic differentiation by signals from blood vessels. Science, 294(5542), 564-7.

Matsumoto, K., Yoshitomi, H., Rossant, J., Zaret, K.S. (2001). Liver organogenesis promoted by endothelial cells prior to vascular function. Science, 294(5542), 559-63.

Compernolle, V., Brusselmans, K., Acker, T., Hoet, P., Tjwa, M., Beck, H., Plaisance, S., Dor, Y., Keshet, E., Lupu, F., Nemery, B., Dewerchin, M., Van Veldhoven, P., Plate, K., Moons, L., Collen, D., Carmeliet, P. (2002). Loss of HIF-2alpha and inhibition of VEGF impair fetal lung maturation, whereas treatment with VEGF prevents fatal respiratory distress in premature mice. Nature Medicine, 8(7), 702-10.

Samuel, S., Ahmad, R. E., Ramasamy, T. S., Karunanithi, P., Naveen, S. V., Murali, M. R., Kamarul, T. (2016). Platelet-rich concentrate in serum free medium enhances osteogenic differentiation of bone marrow-derived human mesenchymal stromal cells. PeerJ, 4, e2347.

Chignon-Sicard, B., Kouidhi, M., Yao, X., Delerue-Audegond, A., Villageois, P., Peraldi, P., Ferrari, P., Rival, Y., Piwnica, D., Aubert, J., Dani, C. (2017). Plateletrich plasma respectively reduces and promotes adipogenic and myofibroblasticdiffe rentiation of human adipose-derived stromal cells via the Scientific Reports, 7(1), 2954.

TGF $\beta$ signalling pathway.

Homayouni Moghadam, F., Tayebi, T., Barzegar, K. (2016). Differentiation of Rat bone marrow Mesenchymal stem cells into Adipocytes and Cardiomyocytes after treatment with platelet lysate. Int J Hematol Oncol Stem Cell Res. 2016 Jan 1;10(1):21-9.

Lee JK1, Lee S, Han SA, Seong SC, Lee MC. The effect of platelet-rich plasma on the differentiation of synovium-derived mesenchymal stem cells. J Orthop Res. 2014 Oct;32(10):1317-25. doi: 10.1002/jor.22668. Epub 2014 Jun 29.

Gruber R1, Karreth F, Kandler B, Fuerst G, Rot A, Fischer MB, Watzek G. (2004) Platelet-released supernatants increase migration and proliferation, and decrease osteogenic differentiation of bone marrow-derived mesenchymal progenitor cells under in vitro conditions. Platelets, 15(1), 29-35.

Naaijkens, B.A., Niessen, H.W.M., Prins, H.J., Krijnen, P.A.J., Kokhuis, T.J.A., de Jong, N., Juffermans, L.J.M. (2012). Human platelet lysate as a fetal bovine serum substitute improves human adipose-derived stromal cell culture for future cardiac repair applications. Cell and Tissue Research, 348(1), 119-130.

Kakudo, N., Minakata, T., Mitsui, T., Kushida, S., Notodihardjo, F. Z., \& Kusumoto, K. (2008). Proliferation-Promoting Effect of Platelet-Rich Plasma on Human Adipose Derived Stem Cells and Human Dermal Fibroblasts. Plastic and Reconstructive Surgery, 122(5), 2235-43.

Lucarelli, E., Beccheroni, A. D., Sangiorgi, L., Cenacchi, A., Del Vento, A. M., Meotti, C., Picci, P. (2003). Platelet-derived growth factors enhance proliferation of human stromal stem cells. Biomaterials, 24(3), 3094-3100. 
594

595

596

597

598

599

600

601

602

603

604

605

606

607

608

609

610

611

612

613

614

615

616

617

618

619

620

621

622

623

624

625

626
Li, H., Usas, A., Poddar, M., Chen, C., Thompson, S., Ahani, B., Cummins, J., Lavasani, M., Huard, J. (2013). Platelet-rich plasma promotes the proliferation of human muscle derived progenitor cells and maintains their stemness. PLOS ONE, 8(6), e64923.

Mishra, A., Tummala, P., King, A., Lee, B., Kraus, M., Tse, V., \& Jacobs, C. R. (2009). Buffered platelet-rich plasma enhances mesenchymal stem cell proliferation and chondrogenic differentiation. Tissue Engineering Part C: Methods, 15(1), 431-435.

Cervellia, V., Sciolib, M. G., Gentilea, P., Doldob, E., Bonannob, E., Spagnolib, L. G., \& Orlandib, A. (2012). Platelet-rich plasma greatly potentiates insulin-induced adipogenic differentiation of human adipose-derived stem cells through a serine/threonine kinase Akt-dependent mechanism and promotes clinical fat graft maintenance. Stem Cells Translational Medicine, $1(5), 206-220$.

Horst, M., Eberli, D., Gobet, R., \& Salemi, S. (2019). Tissue Engineering in Pediatric Bladder Reconstruction-The Road to Success. Frontiers in pediatrics, 7, 91. https://doi.org/10.3389/fped.2019.00091

Karadjian, M.; Senger, A.-S.; Essers, C.; Wilkesmann, S.; Heller, R.; Fellenberg, J.; Simon, R.; Westhauser, F. Human Platelet Lysate Can Replace Fetal Calf Serum as a Protein Source to Promote Expansion and Osteogenic Differentiation of Human Bone-Marrow-Derived Mesenchymal Stromal Cells. Cells 2020, 9, 918.

Trojahn Kølle SF, Oliveri RS, Glovinski PV, Kirchhoff M, Mathiasen AB, Elberg JJ, Andersen PS, Drzewiecki KT, Fischer-Nielsen A. Pooled human platelet lysate versus fetal bovine serum-investigating the proliferation rate, chromosome stability and angiogenic potential of human adipose tissue-derived stem cells intended for clinical use. Cytotherapy. 2013 Sep;15(9):1086-97. doi: 10.1016/j.jcyt.2013.01.217. Epub 2013 Apr 17. PMID: 23602579.

Figure 1: Characterization and differentiation potential of ADSCs. Aa) Primary ADSCs morphology after 14 days in culture under the inverted phase contrast microscope. Scale bar $=$ $100 \mu \mathrm{m}$. B-F) Flow cytometry staining of ADSC markers. Cells showed positive staining for 
627

643

644

645

646

647

648

649

650

651

652

653

654

655

656

657

658

659

660

661

662 mesenchymal stem cells markers CD-44, CD-105, CD-73, CD-90 and negative for CD-34, CD11b, CD-19, CD-45 and HLA-DR in the negative cocktail.

Figure 2: Multilineage differentiation potential of ADSCs. A\&C) Osteogenic mineral deposition was observed after 21 days of osteogenic induction and positively stained with Alizarin Red S stain (ARS). B\&D) Uninduced ADSCs were used as a negative control and stained negatively with ARZ. E\&G) Lipid droplets were observed after 14 days of adipogenic differentiation of ADSCs and positively stained with Oil Red O. F\&H) ADSCs with normal culture media stained negatively for oil red O. Scale bar $=100 \mu \mathrm{m}$. All differentiation experiments were repeated at least three times

Figure 3. Relative gene expression of urothelial markers. Real time-PCR performed on urotheliallike cells differentiated from ADSCs, cultivated in either conditioned medium (CM) or unconditioned urothelial cell media (UCM) in the presence of either $5 \% \mathrm{pHPL}, 2.5 \% \mathrm{pHPL}$ or $10 \%$ FBS. Uninduced ADSCs were used as the calibrator sample. A) Relative expression of cytokeratin-18, B) cytokeratin-19 and $\mathbf{C}$ ) uroplakin-2. $* P<0.05, * * \mathrm{P}<0.01$. All experiments were repeated at least three times.

Figure 4. Immunofluorescence staining of urothelial markers at the cellular level. A) ADSCs cultured in CM and different concentrations of pHPL (5\% \& $2.5 \%)$ or with FBS, were assessed for the expression of cytokeratin-18 (FITC, green) and uroplakin- 2 (Cy3, red). SV-HUC cells were used as a positive control, meanwhile ADSCs were utilized as a negative control. Scale bar $=50 \mu \mathrm{m}$. B\&C) Semi-quantitative analysis of immunoflouresence representing percentage of positive cells relative to negative control. All experiments were repeated at least three times.

Figure 5. Growth factor levels assessment in induced ADSCs. Enzyme linked immunosorbent assay (ELISA) was preformed on conditioned media collected after 24 hours from cells induced for 14 days with urothelial cell derived conditioned medium (CM) or unconditioned urothelial cell media (UCM) with 5\% pHPL, 2.5\%pHPL or FBS. A) Measurement of epidermal growth factor levels (EGF). B) Platelet derived growth factor-BB (PDGF-BB). C) Vascular endothelial growth factor (VEGF). $* P<0.05, * * \mathrm{P}<0.01$. All experiments were repeated at least three times. 
Figure 1

Characterization and differentiation potential of ADSCs.

Characterization and differentiation potential of ADSCs. Aa) Primary ADSCs morphology after

14 days in culture under the inverted phase contrast microscope. Scale bar $=100 \mu \mathrm{m}$. B-F)

Flow cytometry staining of ADSC markers. Cells showed positive staining for mesenchymal

stem cells markers CD-44, CD-105, CD-73, CD-90 and negative for CD-34, CD-11b, CD-19, CD-45 and HLA-DR in the negative cocktail. 
A)
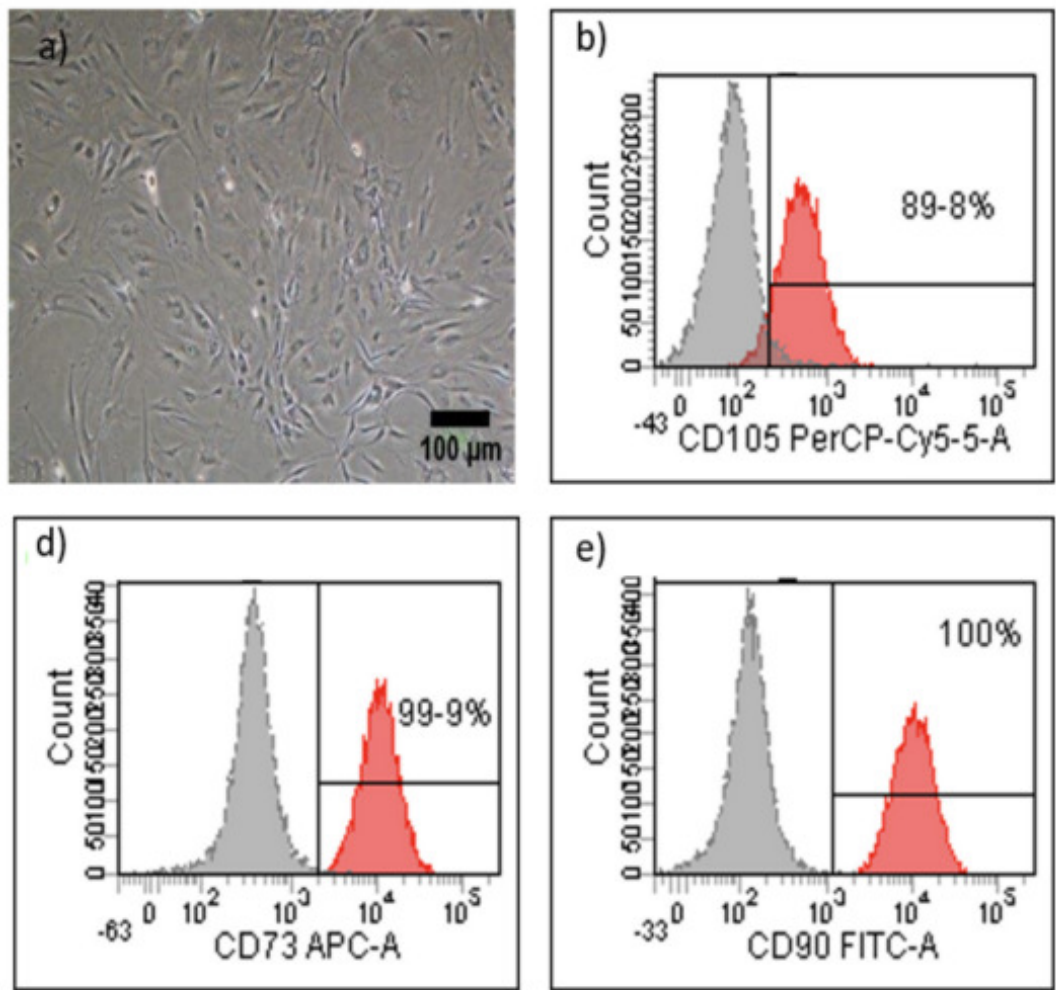

e)

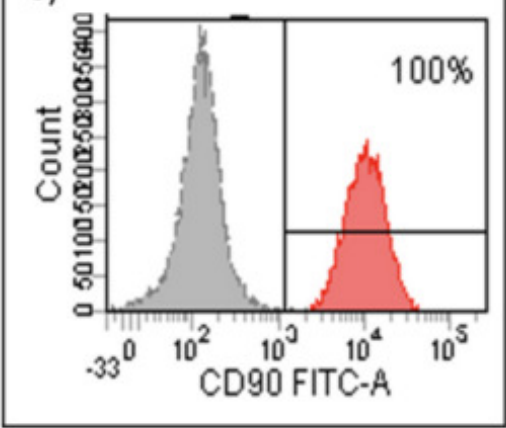

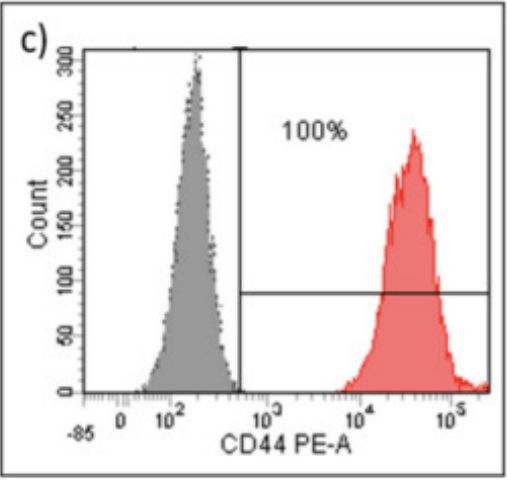

f)

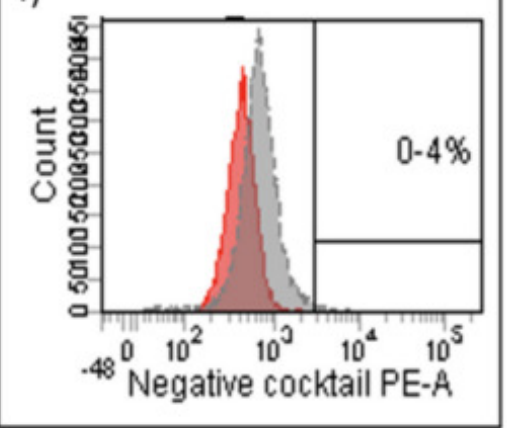

\section{B)}
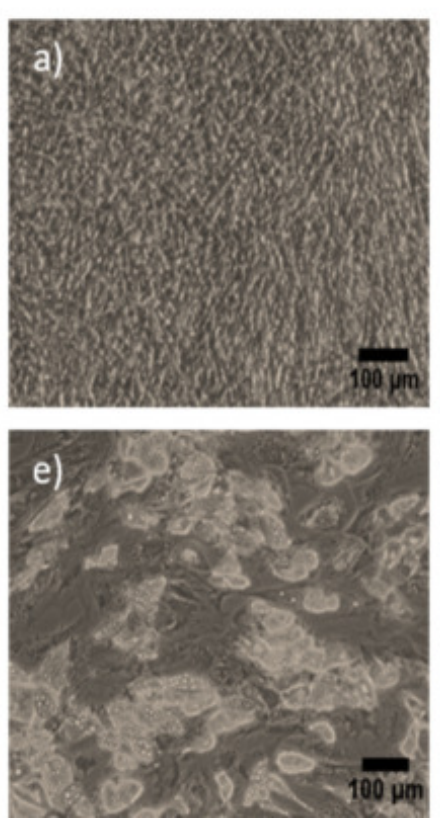
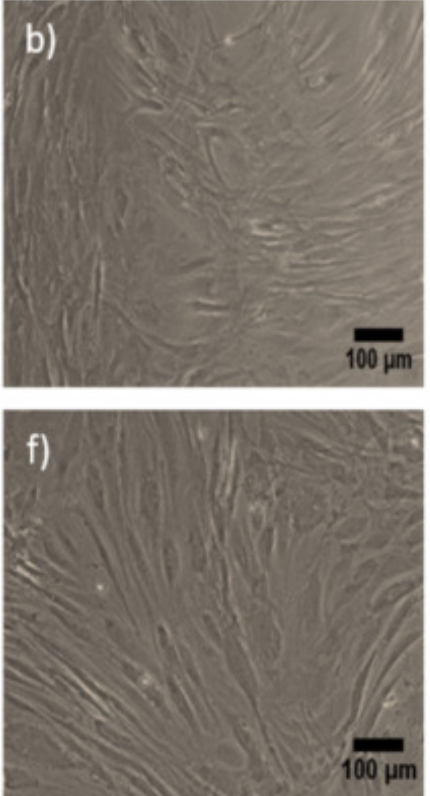
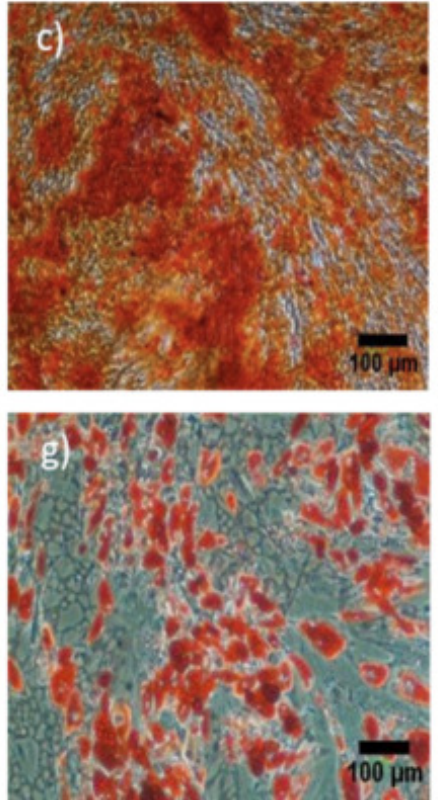

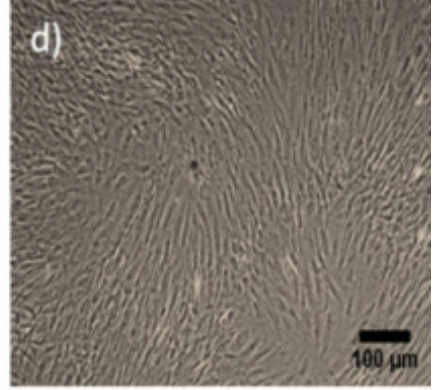

h) 


\section{Figure 2}

Figure 2: Multilineage differentiation potential of ADSCs.

Figure 2: Multilineage differentiation potential of ADSCs. A-C) Osteogenic mineral deposition was observed after 21 days of osteogenic induction and positively stained with Alizarin Red S stain (ARS). B-D) Uninduced ADSCs were used as a negative control and stained negatively with ARZ. E-G) Lipid droplets were observed after 14 days of adipogenic differentiation of ADSCs and positively stained with Oil Red O. F-H) ADSCs with normal culture media stained negatively for oil red O. Scale bar $=100 \mu \mathrm{m}$. All differentiation experiments were repeated at least three times
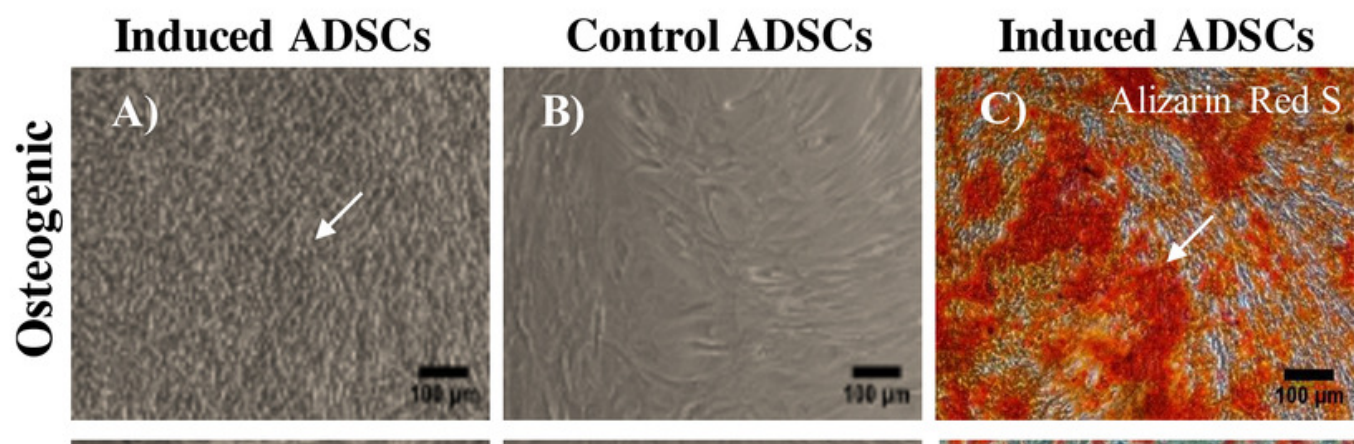

\section{Control ADSCs}
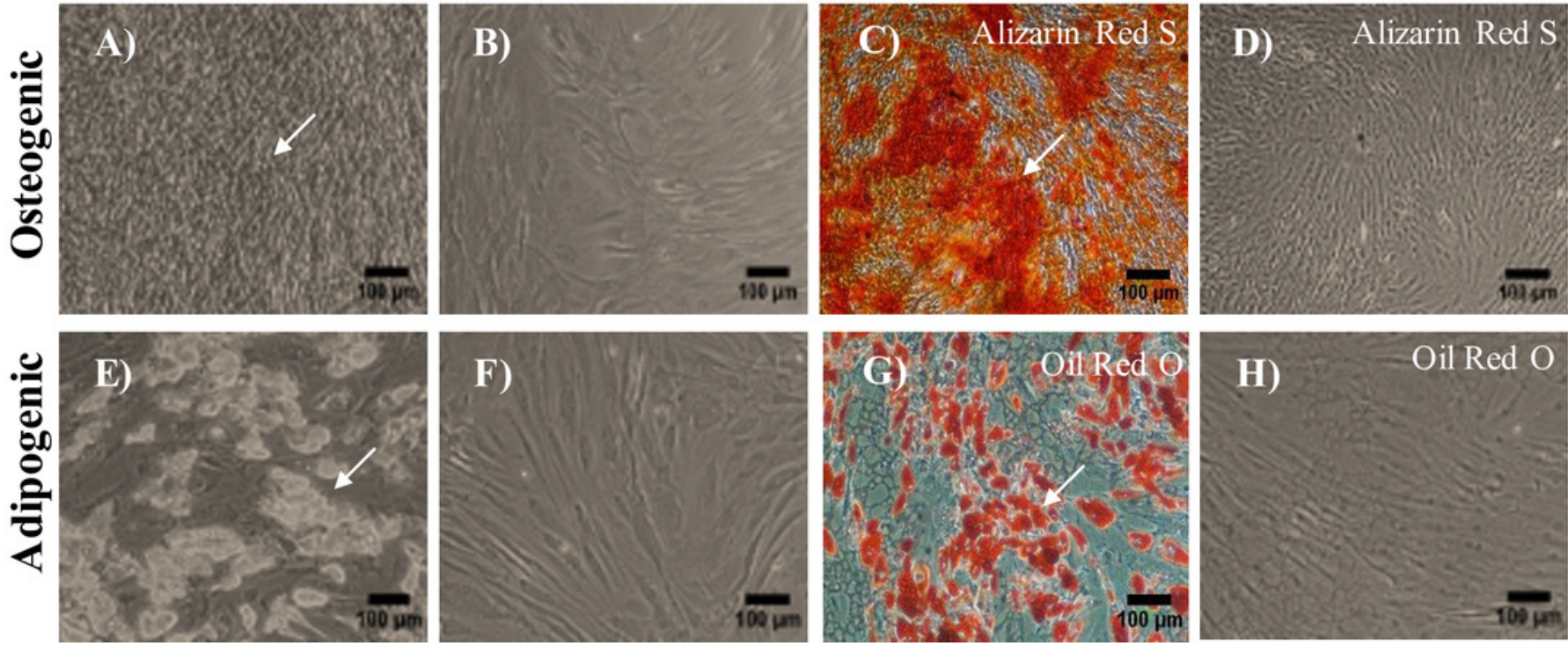

H)

Oil Red O 


\section{Figure 3}

Figure 3. Relative gene expression of urothelial markers.

Figure 3. Relative gene expression of urothelial markers. Real time-PCR performed on urothelial-like cells differentiated from ADSCs, cultivated in either conditioned medium (CM) or unconditioned urothelial cell media (UCM) in the presence of either 5\% pHPL, 2.5\% pHPL or $10 \% \mathrm{FBS}$. Uninduced ADSCs were used as the calibrator sample. A) Relative expression of cytokeratin-18, B) cytokeratin-19 and C) uroplakin-2. $* P<0.05$, $* * P<0.01$. All experiments were repeated at least three times. 
A)

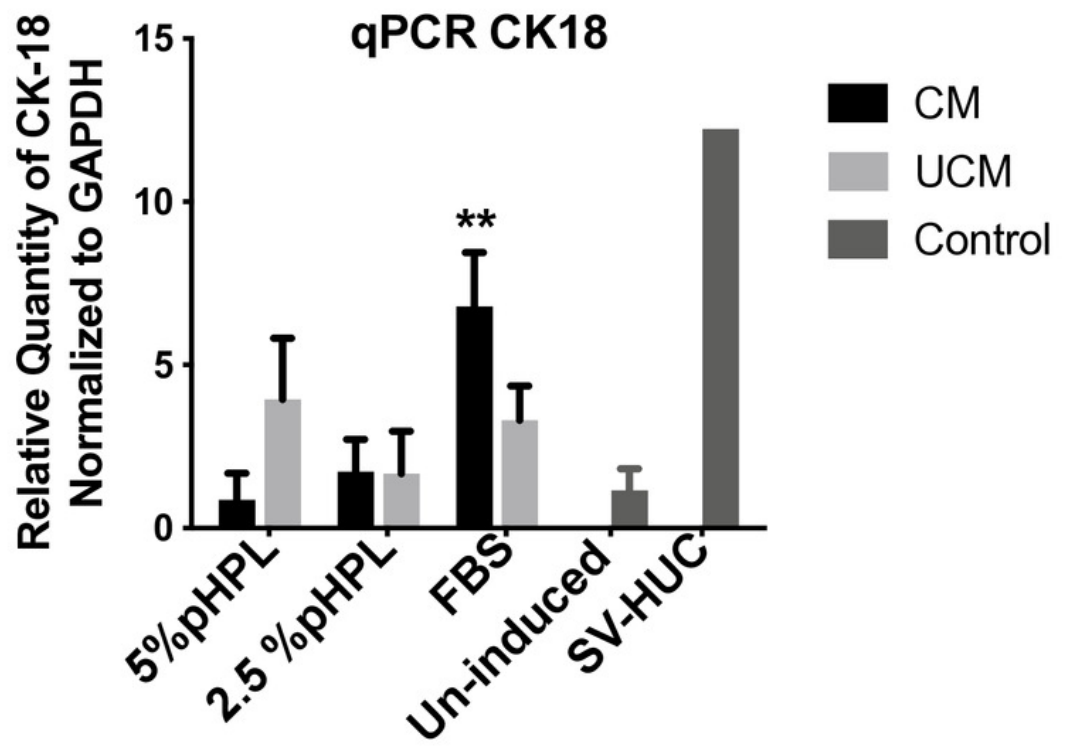

B)

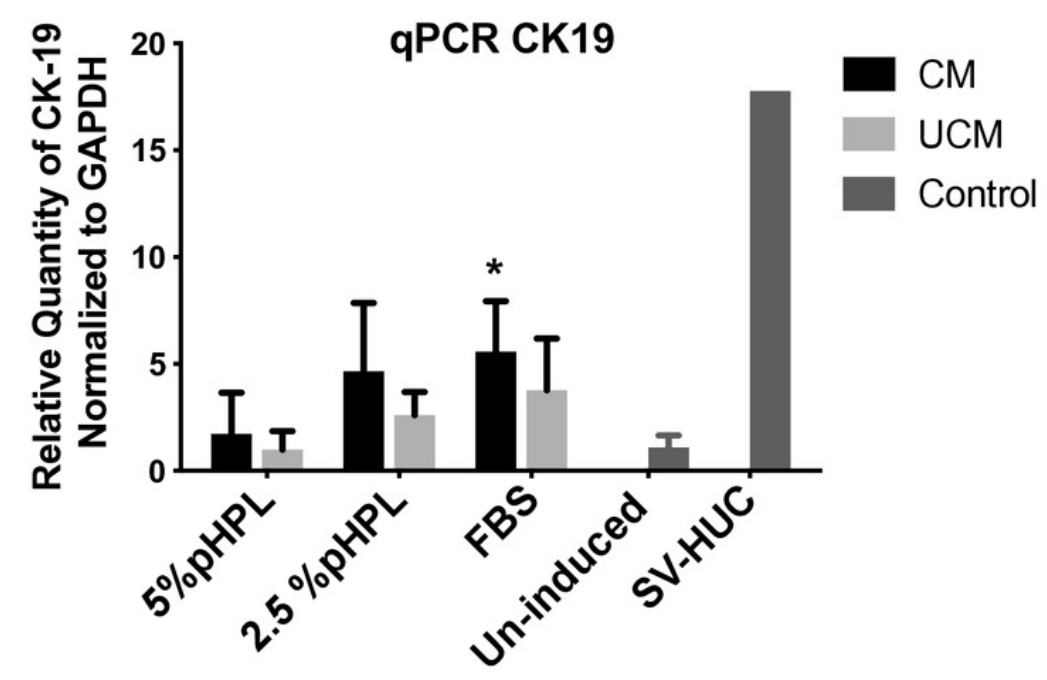

C)

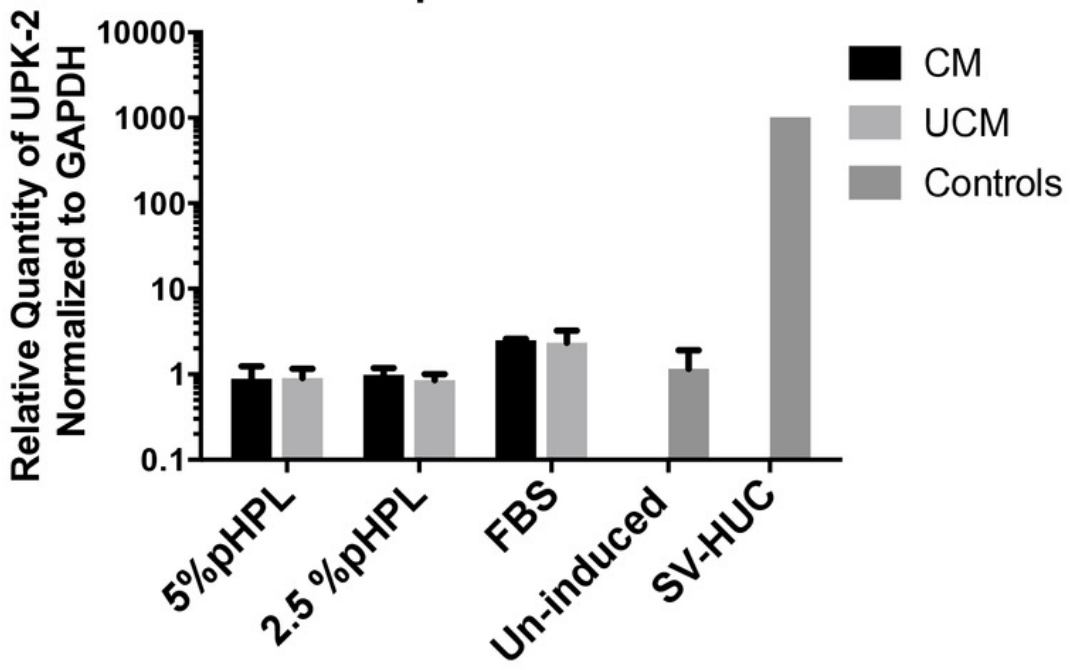




\section{Figure 4}

Immunofluorescence staining of urothelial markers at the cellular level

Immunofluorescence staining of urothelial markers at the cellular level. A) ADSCs cultured in $\mathrm{CM}$ and different concentrations of pHPL ( $5 \% \& 2.5 \%)$ or with FBS, were assessed for the expression of cytokeratin-18 (FITC, green) and uroplakin- 2 (Cy3, red). SV-HUC cells were used as a positive control, meanwhile ADSCs were utilized as a negative control. Scale bar $=50 \mu \mathrm{m}$. B\&C) Semi-quantitative analysis of immunoflouresence representing percentage of positive cells relative to negative control. All experiments were repeated at least three times. 
A)

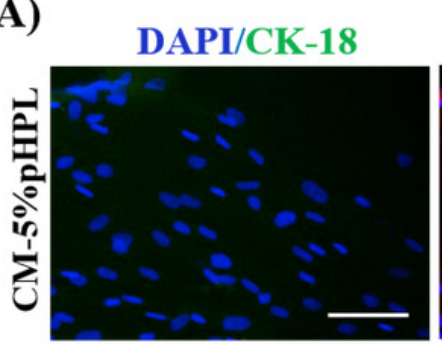

DAPI/UPK-2
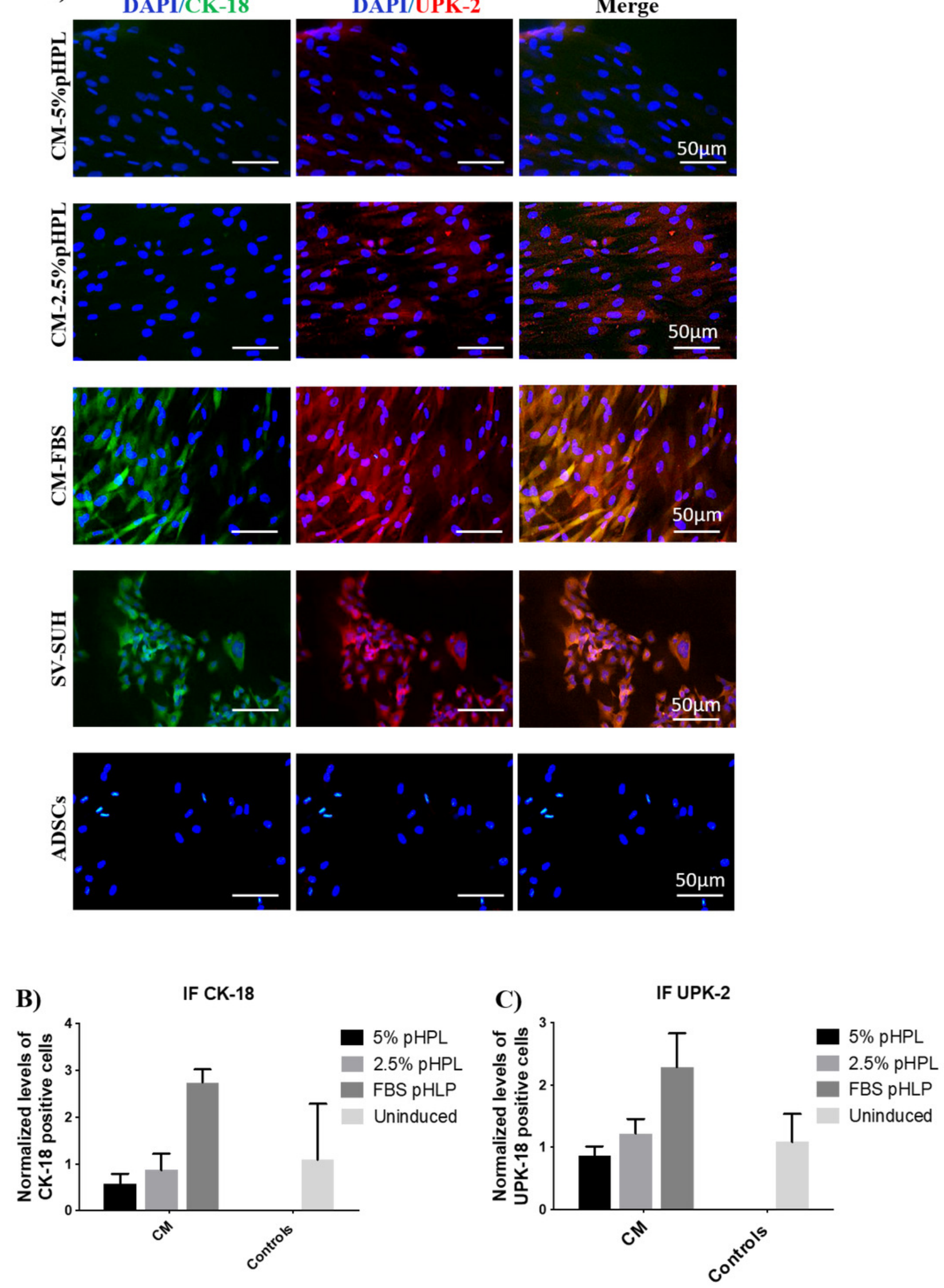


\section{Figure 5}

Figure 5. Growth factor levels assessment in induced ADSCs.

Enzyme linked immunosorbent assay (ELISA) was preformed on conditioned media collected after 24 hours from cells induced for 14 days with urothelial cell derived conditioned medium (CM) or unconditioned urothelial cell media (UCM) with 5\% pHPL, 2.5\%pHPL or FBS. A) Measurement of epidermal growth factor levels (EGF). B) Platelet derived growth factor-BB (PDGF-BB). C) Vascular endothelial growth factor (VEGF). $* P<0.05, * * P<0.01$. All experiments were repeated at least three times. 
A)

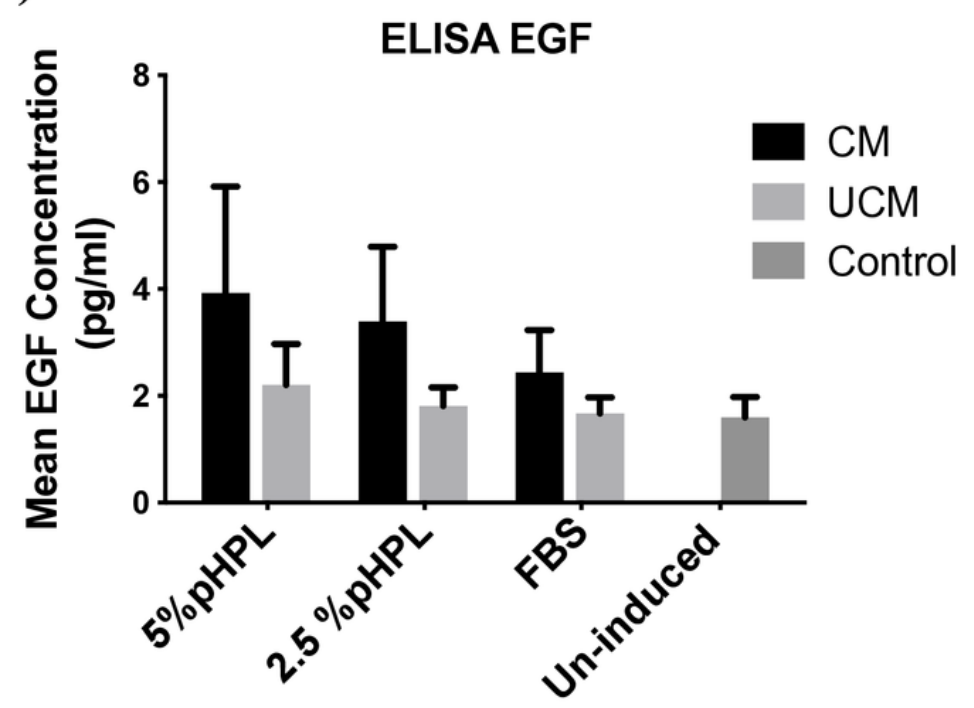

B)

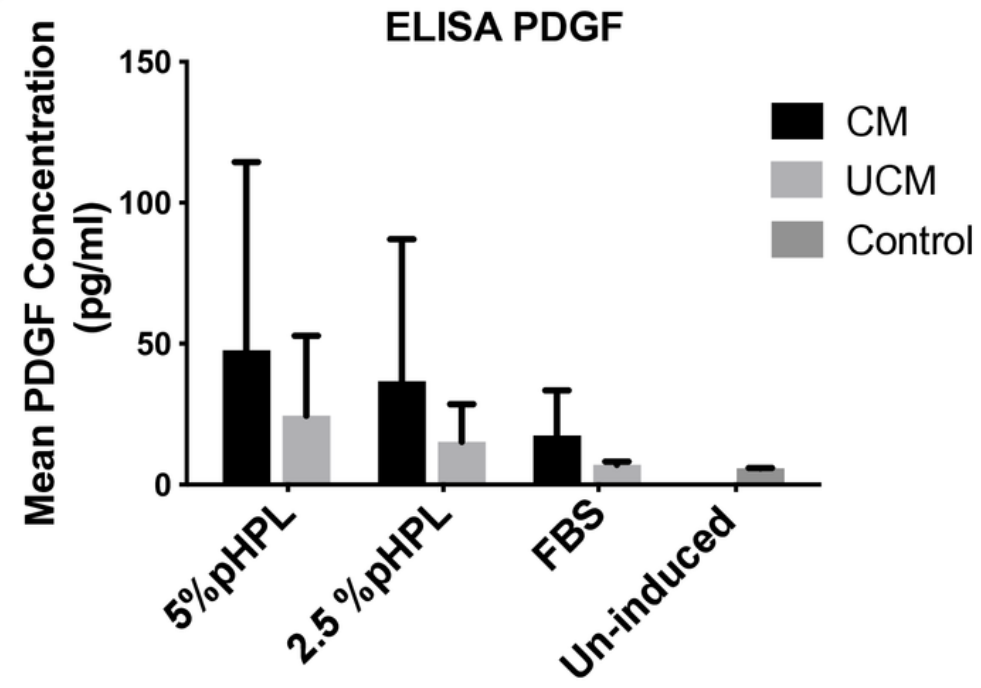

C)

ELISA VEGF

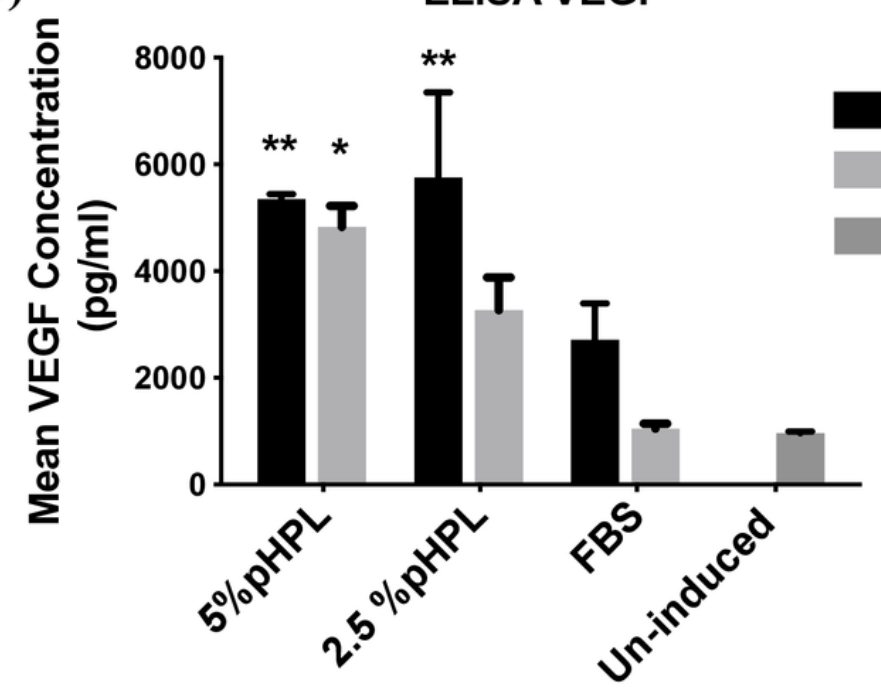


Table $\mathbf{1}$ (on next page)

Table 1. qPCR primer sequences.

Table 1. qPCR primer sequences. 
1 Table 1. qPCR primer sequences.

\begin{tabular}{|l|l|l|}
\hline Gene & Forward Primer & Reverse Primer \\
\hline Uroplakin-2 & $\begin{array}{l}\text { CGGAGAGCCGACAGCAAA } \\
\text { C }\end{array}$ & ACTGAGCCGAGTGACTGTGAAG \\
\hline Cytokeratin-18 & $\begin{array}{l}\text { GGTCAGAGACTGGAGCCA } \\
\text { TTA }\end{array}$ & GGCATTGTCCACAGTATTTGC \\
\hline Cytokeratin-19 & CGGGACAAGATTCTTGGT & CCTTGATGTCGGCCTCCA \\
\hline GAPDH & CAAGGTTGACAACTTTG & GGGCCATCCACAGTCTTCTG \\
\hline
\end{tabular}

2

3

4 